\section{Pain in the eye: a case of gonococcal orbital cellulitis}

Orbital cellulitis (OC) causes inflammation of the ocular soft tissues posterior to the orbital septum. ${ }^{1}$ Untreated OC can cause serious complications including vision loss. Bacterial OC caused by Neisseria gonorrboea is exceedingly rare. ${ }^{2}$ Here, we present the third reported case in the literature of postseptal gonococcal OC in adults. A 39-year-old woman presented with progressive eye swelling, drainage and pain (figure 1). She denied any ocular trauma or recent sinusitis. A CT scan of the maxillofacial region was consistent with OC. The patient was initiated on intravenous ceftriaxone with marked improvement by hospital day 2. Wound culture taken from the patient's eye grew
N. gonorrhoea, and the urine nucleic acid amplification test was positive for N. gonorrhoea. On hospital day 3, the patient left against medical advice and was discharged with oral ciprofloxacin, which was modified to cefixime after returning to the hospital 1 day following discharge. Her gonococcal culture showed sensitivity to cefixime and ciprofloxacin. On followup, the patient noted compliance with her cefixime, stable vision and complete resolution of her orbital symptoms.

OC is usually a result of sinusitis or trauma, but this patient's OC was likely caused by self-inoculation, consistent with other case reports of gonococcal eye infections. ${ }^{2}$ Management of gonococcal OC is challenging given lack of guidelines and increasing gonococcal resistance to oral antibiotics. ${ }^{3}$ In order to effectively treat this serious disease, it is essential to test the isolate for resistance patterns.

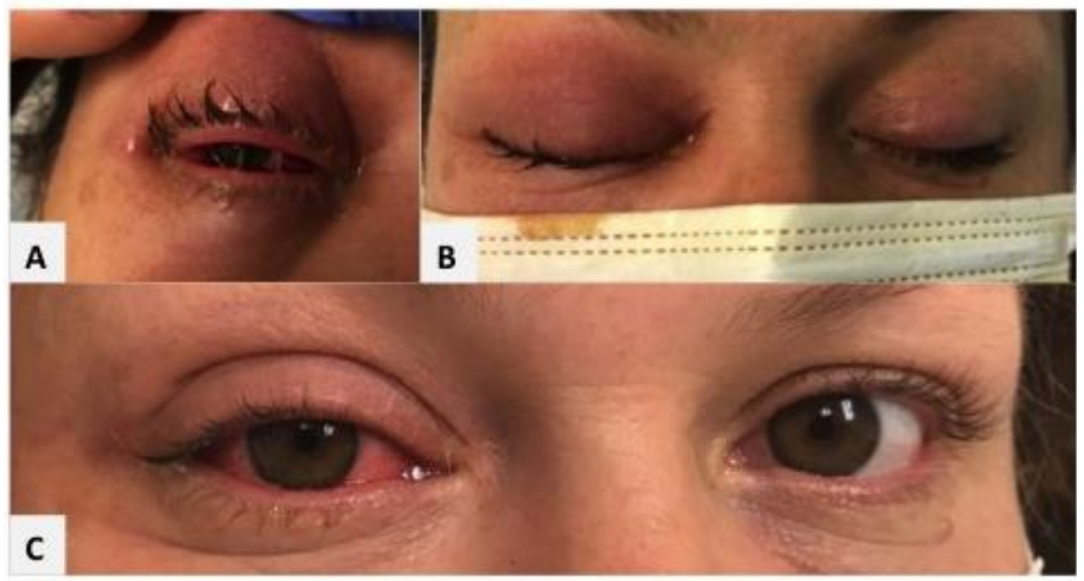

Figure 1 Images of the patient's eye. $(A, B)$ On presentation. The right eye is erythematous, swollen, with purulent drainage and mild proptosis. (C) On hospital day 3. The right eye has notable decreased swelling, decreased drainage.
Sophie Miller, ${ }^{1,2}$ Tyler Degener, $^{1,2}$ Pruthul Patel $\oplus^{3}$

IInternal Medicine, LAC+USC Medical Center, Los Angeles, California, USA

${ }^{2}$ Internal Medicine, Keck School of Medicine of USC, Los Angeles, California, USA

Internal Medicine and Pediatrics, LAC+USC Medical

Center, Los Angeles, California, USA

Correspondence to Dr Pruthul Patel, Internal Medicine and Pediatrics, LAC USC Medical Center, Los Angeles, CA 90033, USA; ppatel@dhs.lacounty.gov

Funding The authors have not declared a specific grant for this research from any funding agency in the public, commercial or not-for-profit sectors.

Competing interests None declared.

Patient consent for publication Not required.

Provenance and peer review Not commissioned; internally peer reviewed.

(C) Author(s) (or their employer(s)) 2021. No commercial re-use. See rights and permissions. Published by BMJ.

\section{Check for updates}

To cite Miller S, Degener T, Patel P. Sex Transm Infect 2021:97:320.

Received 26 October 2020

Accepted 30 October 2020

Published Online First 18 November 2020

Sex Transm Infect 2021;97:320.

doi:10.1136/sextrans-2020-054850

\section{ORCID iD}

Pruthul Patel http://orcid.org/0000-0002-5684-315X

\section{REFERENCES}

1 Raja NS, Singh NN. Bilateral orbital cellulitis due to Neisseria gonorrhoeae and Staphylococcus aureus: a previously unreported case. J Med Microbiol 2005:54:609-11.

2 Oliveira I, Mouzinho A, Marques JG. Gonococcal orbital cellulitis. BMJ Case Rep 2019:12:e227787-9.

3 Centers for Disease Control and Prevention. Sexually transmitted disease surveillance 2017: gonococcal isolate surveillance project (GISP) supplement and profiles. Atlanta: U.S. Department of Health and Human Services, 2019 